\section{$\underset{\substack{\text { hommes } \\ \text { \& migrations }}}{ }$}

\section{Hommes \& migrations}

Revue française de référence sur les dynamiques

migratoires

$1324 \mid 2019$

Religion et discrimination

\title{
Allée des jasmins
}

Court-métrage France, 2018, de Stéphane Ly-Cuong

\section{Mouloud Mimoun}

\section{OpenEdition \\ 1 Journals}

\section{Édition électronique}

URL : https://journals.openedition.org/hommesmigrations/8640

DOI : 10.4000/hommesmigrations.8640

ISSN : 2262-3353

\section{Éditeur}

Musée national de l'histoire de l'immigration

\section{Édition imprimée}

Date de publication : 1 janvier 2019

Pagination : 219-220

ISBN : 978-2-919040-44-5

ISSN : $1142-852 X$

\section{Référence électronique}

Mouloud Mimoun, «Allée des jasmins », Hommes \& migrations [En ligne], 1324 | 2019, mis en ligne le

01 janvier 2019, consulté le 06 janvier 2022. URL : http://journals.openedition.org/

hommesmigrations/8640 ; DOI : https://doi.org/10.4000/hommesmigrations.8640 


\section{Films}

\section{Allée des jasmins}

Court-métrage de Stéphane Ly-Cuong (France, 2018)

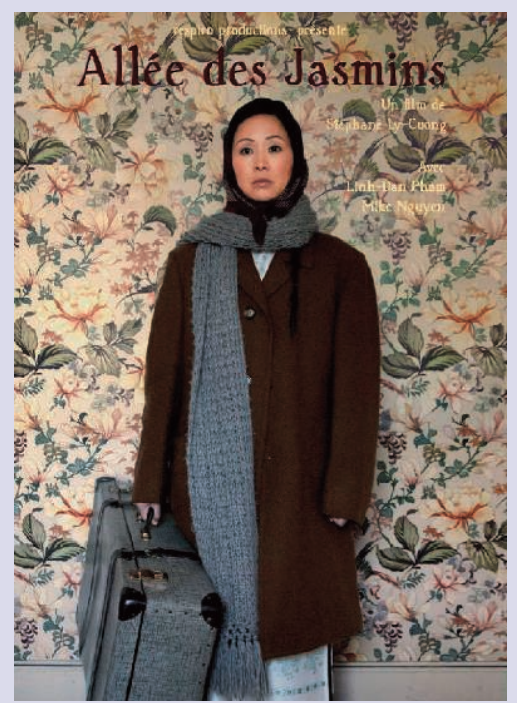

Rares, sinon inexistantes, sont les œuvres cinématographiques de fiction qui ont témoigné de l'exode des populations vietnamiennes dans les années 1960, et surtout 1970, qui ont rejoint la France. Certes, ici ou là, reportages et documentaires ont surtout évoqué la vague d'émigration au lendemain de la chute de Saïgon le 30 avril 1975, lorsque des milliers de Vietnamiens ont fui le Sud pour échapper au régime communiste à venir. On se souvient aussi de ceux qu'on a rebaptisé «boat people» et des actions humanitaires, notamment de Bernard Kouchner alors en première ligne des médias. Mais, avec Allée des jasmins de Stéphane Ly-Cuong, courte fiction de vingt minutes, ce ne sont pas ces événements marquants qui sont évoqués... c'est l'histoire d'un couple, d'une famille, qui débarque dans les années 1960. Pierre et Loan 
sont mari et femme, lui Eurasien, elle Vietnamienne. Ils s'installent en Auvergne, dans l'Allier plus précisément, et le film est le récit de leur intégration progressive à la société d'accueil.

Sans doute grandement autobiographique, l'histoire de leur vie française est loin d'être un long fleuve tranquille. Les images du générique de ce film de 2018 évoquent, à partir d'archives, la guerre et les exodes. Le film s'ouvre ensuite sur le jeune couple pris en charge par les services d'accueil et qui loge dans une fermette où l'autel des ancêtres est le premier espace aménagé par l'épouse, Loan, signe d'un fort attachement au pays d'origine. D'ailleurs, dans une scène dialoguée, elle affirme à son époux: «De toute façon on ne restera pas longtemps.» Pierre en est moins convaincu et va trouver un travail sur des chantiers où il est en charge des toitures. Optimiste, il promet à son épouse une maison et Paris, la capitale! Mais les événements vont contrarier leurs projets. Alors que Loan accouche d'une petite Isabelle, Pierre perd la vie dans un accident du travail. Dès lors, Loan va devoir se débrouiller seule et assumer la charge de sa petite fille. Elle est serveuse dans un café fréquenté par des compatriotes et découvre sur le petit écran les images de la chute de Saigon et la fuite en masse de nombreux Vietnamiens convergeant vers les ambassades occidentales, dont la France. Lesannées s'écoulent lentement et quelques séquences s'inscrivent dans le temps, marquant la transformation d'Isabelle, de fillette en adolescente puis en adulte, et qui se prépare à la fin à visiter son pays d'origine.

Ce film est réalisé avec beaucoup de sobriété et de simplicité. Les comédiens sont remarquablement dirigés, dégageant chacun une forte crédibilité. Quant au spectateur, il ressent émotion et empathie pour les deux protagonistes de cette remarquable Allée des jasmins.

M. M. 